\title{
Analyzing the effects of exercise prescribed based on health-related fitness assessment among different somatotypes
}

\author{
Vijayakumar Kathirgamam, Mandar Ambike*, Raju Bokan, Vaishaly Bharambe, Arun Prasad
}

Department of Anatomy, Symbiosis Medical College for Women, Symbiosis International (Deemed University), Lavale, Pune, India

\begin{abstract}
Introduction: Human body types (somatotypes) are classified into ectomorph, mesomorph, and endomorph. The ectomorphs are physically weak and usually tall. Mesomorphs were characterized as muscular, thick skinned with good upright posture. Endomorphs characterized as fat, heavy, and usually short.

Methods: This study is an interventional study, in which a total number of 45 healthy male volunteers between the age group of 22 and 28 years were observed. Written consent was obtained from the patients after a detailed explanation of the study. Exercises were prescribed and executed based on the American College of Sports Medicine (ACSM) guidelines for exercise testing and prescription. Body composition, cardiorespiratory endurance, muscular strength, muscular endurance, and flexibility were assessed.
\end{abstract}

Results: The statistical analyses were done using the SPSS software version 16 executed at a 95\% confidence interval. Mean and standard deviations were calculated by descriptive statistics. A paired t-test was done to find the effectiveness of the intervention. The level of significance in all tests was set to $p<0.05$. Positive changes were observed in health-related fitness among the three groups.

Conclusion: This study reports about finding the somatotypes, and exercising based on that will provide the best results in health-related fitness components designed by the ACSM.

Keywords: Somatotypes; American College of Sports Medicine; ectomorphs; endomorphs; mesomorphs; exercise prescription

\section{INTRODUCTION}

Humans are born with a specific genetic body type, distinctive skeletal framework, and varying body composition (1). Human body types (somatotypes)

*Corresponding author: Mandar Ambike, Department of Anatomy, Symbiosis Medical College for Women, Symbiosis International (Deemed University), Pune, Maharashtra, India. Phone: +91-9940695046. E-mail: assoprof.anatomy1@smcw.siu.edu.in

Submitted: 04 January 2020/Accepted: 19 March 2020

DOI: https://doi.org/10.17532/jhsci.2020.876

UNIVERSITY OF SARAJEVO FACULTY OF HEALTH STUDIES are classified into ectomorph, mesomorph, and endomorph $(2,3)$. Somatotypes provide complete information about the morphology and features of the human body (4). Lewandowska J et al (5) studied the muscle power and torque among 14 volley ball players based on the somatotypes and reported that mesomorphs had the more ability to elicit a greater amount of muscle torque. The performances such as countermovement jump, spike jump among 14 volleyball players based on somatotypes. Mesomorphs have large and well-developed muscles and they are 
capable of producing powerful movements $(6,7)$. William Herbert Sheldon an American Psychologist studied the behavioral analysis based on body types, by taking and using the naked photographs of more than a thousand undergraduate students in the 1940s and he termed it as somatotypology (8). Elazizi classified the female body types for standardization of textiles, based on shapes, such as rectangle, triangle, oval, diamond, and hourglass shape (9). Ectomorphs were characterized as skinny, thin, slender, flat-chested lightly lean muscled. Heath-Carter introduced anthropometric, photoscopic, and combination of both anthropometric and photoscopic methods of evaluating the different types of somatotypes (10). The ectomorphs are physically weak and usually tall, described as intelligent, they may feel inferior but perfectionist and very sensitive to pain (11). Mesomorphs were characterized as muscular, thick skinned with good upright posture; they are energetic, determine, and mostly aggressive (12). Endomorphs characterized as fat, heavy, and usually short, they are lazy, selfish, and slow to react (13). Sanchez-Munoz et al. identified the formula classify the somatotypes based on the skinfold thickness measurements (14). Somatotype formulations have been used in both the academics and fitness industries and to categorize an individual's body types (15). Nutrition and fitness professionals utilize the classifications for designing the exercise and diet plans, but how accurate are they? There is no substantial research to show the effects of exercises based on somatotypes. Therefore, to address these issues, the present study attempts to evaluate the effects of exercise intervention based on health-related fitness assessment, which was prescribed based on somatotypes according to the American College of Sports Medicine (ACSM).

\section{METHODS}

This study is an interventional study, in which a total number of 45 healthy male volunteers between the age group of 22 and 28 years were included, and the study was conducted in a fitness center in Chennai, the duration of the study was 3 months. Individuals with recent fractures, open wounds, ulcers, uncontrolled hypertension (systolic blood pressure $>180 \mathrm{mmHg}$ or diastolic blood pressure
$>100 \mathrm{mmHg}$ ) or other cardiovascular diseases, any major active rheumatologic, pulmonary, hepatic, renal, dermatologic disease, or inflammatory conditions were excluded from the study. Ethical approval was obtained from the Institutional Ethics Committee of Sri Ramachandra Medical College and Research Institute, Tamil Nadu, Chennai. Written consent was obtained from the patients after a detailed explanation of the study, their role, risks, and benefits involved, and their rights. For this survey, we used fitness equipment's in the fitness center, standard height and weight measuring scale and tape, sit and reach the box, pulse oximeter, sphygmomanometer, and stationary materials.

After enrollment in the study, all participants were given a pre-assessment health questionnaire, consists of past and present medical history, lifestyle information, dietary patterns, and level of physical activity and exercise. Based on the questionnaire result, the participants were selected for the subjective assessment. Participants with risk factors for assessment and the exercises were excluded at this stage (ACSM Ehrman, 2010) (16). Basic subjective assessments such as height and weight were measured and body mass index (BMI) was calculated.

\section{Health-related physical fitness assessment Body composition}

Skinfold measurements were done using a standard skinfold caliper, the skinfold measurements were made at chest, abdomen, and mid-thigh (17).

\section{Cardiorespiratory endurance}

One mile walk test was conducted using a treadmill to estimate the maximal oxygen consumption, after a few trials of walking to get familiarize with treadmill, the participants were instructed for a brisk walk at their comfortable speed to cover the distance of 1 mile, after completion of 1 mile, the heart rate (HR) was measured using pulse oximeter and time was noted (18).

\section{Muscular strength}

Leg press machine was used to assess muscular strength; the technique was demonstrated and performed by the investigator before assessing the participants. About $50-70 \%$ of the subject's perceived capacity was selected as initial weight. 
With few trials and familiarization with the machine, resistance was progressively increased by $2.5-20.0 \mathrm{~kg}$ until the subject could not complete the selected repetition(s); all repetitions were performed at full range of motion (ROM) in the same speed of movement with normal inhalation and exhalation. The final weight lifted effectively is noted as the absolute 1 - repetition maximum (RM) (19).

\section{Muscular endurance}

The push-up test was conducted to assess the muscular endurance, the participants were instructed to position the body with arms straight out, with contracted abdominal muscles tight and not to hold the breath and holding the body in a prone position. Then, lower the body until the chest is in one or two inches above the floor, with elbows pulling back at roughly a $45^{\circ}$ angle, then push the torso away from the ground until the arms lock, then repeat. Instructions were given to maintain the normal breath during the procedure (20).

\section{Flexibility}

Assessment of low back and hamstring was done by a sit and reach test using sit and reach measuring box. The subject was made to sit on the floor with knees locked, legs stretched out, and the feet were kept flat against the box. With palms facing downward, the hands were kept on top of each other. The subject moved the hand forward along the measuring scale as far as possible without any jerky movements, when the maximum level has reached the subject remained for 1-2 seconds and the distance was noted $(21,22)$.

Based on the assessment and observation, the participants were categorized as ectomorph (Group - A), mesomorph (Group - B), and endomorph (Group - C) which are shown in Figures 1A-C, respectively. The characteristics of the subjects was shown in Table 1 . The exercise intervention was appropriately prescribed and executed based on the guidelines provided by the ACSM for the duration of 3 months, as shown in Table 2.

\section{Intervention}

Exercises were prescribed and executed based on the ACSM guidelines for exercise testing and prescription (23-30).

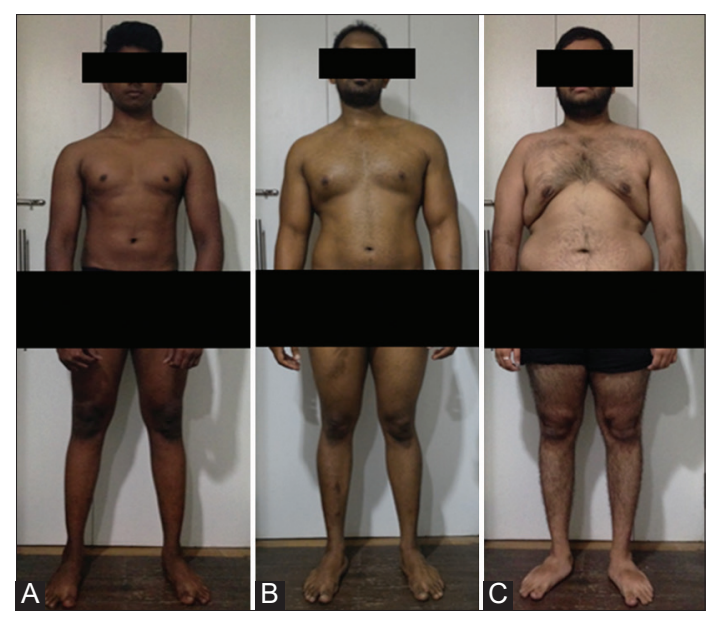

FIGURE 1. Different body types (somatotypes) (A) Ectomorph, (B) mesomorph, (C) endomorph.

TABLE 1. The characteristics of subjects mean (SD)

\begin{tabular}{lcc}
\hline Age mean (SD) & Height mean (SD) & Weight mean (SD) \\
\hline $23.6(5.2)$ & $176(3.4)$ & $79.4(11.5)$ \\
\hline
\end{tabular}

SD: Standard deviations

\section{RESULTS}

The statistical analyses were done using the SPSS software version 16 executed at 95\% confidence interval (CI). Mean and standard deviations (SD) were calculated by descriptive statistics. The paired t-test was done to find the effectiveness of the intervention. The level of significance in all tests was set to $p<0.05$.

The designed protocol for intervention based on somatotypes brought about significant improvement in health-related fitness parameters in ectomorphs, mesomorphs, and endomorphs. The preand post-exercise intervention for Groups A, B, and $\mathrm{C}$ are shown in Tables 3-5, respectively.

Cardiovascular endurance and the resting HR showed a positive change in all three groups. No significant weight loss was observed in Groups $\mathrm{A}$ and B since Group C had shown a significant reduction of weight (mean difference of 9.18 [1.52] kg and its 95\% CI: 8.35-11.16), as shown in Tables 3, 4 and 5. The BMI and percentage of fat in the skinfold also recorded a significant reduction in Group C of $5.11(1.04) \mathrm{kg} / \mathrm{m}^{2}$ and $2.61(0.21)$, respectively. Groups A, B, and C had responded equally well to 
TABLE 2. The exercise prescribed and executed based on the ACSM for different somatotypes

\begin{tabular}{|c|c|c|c|}
\hline $\begin{array}{l}\text { Exercise prescribed by the } \\
\text { ACSM guidelines }\end{array}$ & Ectomorph & Mesomorph & Endomorph \\
\hline Warm-up & $\begin{array}{l}\text { Joint mobilization } \\
\text { Low step kicks } \\
\text { (10 min/session) }\end{array}$ & $\begin{array}{l}\text { Joint mobilization } \\
\text { Low-to-moderate aerobic exercises } \\
\text { (10 min/session) }\end{array}$ & $\begin{array}{l}\text { Joint mobilization } \\
\text { Low-to-moderate aerobic } \\
\text { exercises (10 } \mathrm{min} / \mathrm{session})\end{array}$ \\
\hline Flexibility & $\begin{array}{l}\text { Active stretching of all major } \\
\text { muscles and other tightened } \\
\text { muscles based on assessment } \\
\text { results. (10 min/session) }\end{array}$ & $\begin{array}{l}\text { Active stretching of all major muscles } \\
\text { and other tightened muscles based } \\
\text { on assessment results ( } 10 \mathrm{~min} / \\
\text { session) }\end{array}$ & $\begin{array}{l}\text { Active stretching of all } \\
\text { major muscles and other } \\
\text { tightened muscles based } \\
\text { on assessment results } \\
\text { (10 min/session) }\end{array}$ \\
\hline $\begin{array}{l}\text { Cardiovascular } \\
\text { conditioning }\end{array}$ & $\begin{array}{l}\text { Weekly } 2-3 \text { days } \\
10-15 \mathrm{~min} / \mathrm{session} \\
\text { METs }-1.1-2.9\end{array}$ & $\begin{array}{l}\text { Weekly } 3-4 \text { days } \\
20-30 \text { min/session } \\
\text { METs }-3-4\end{array}$ & $\begin{array}{l}\text { Weekly } 5 \text { days } \\
30-40 \mathrm{~min} / \mathrm{session} \\
\text { METs }-4-5.9\end{array}$ \\
\hline Core strengthening & $\begin{array}{l}\text { Quadruped position } \\
\text { 3-4 days/week }\end{array}$ & $\begin{array}{l}\text { Plank position } \\
3-4 \text { days/week }\end{array}$ & $\begin{array}{l}\text { Pelvic bridging } \\
3-4 \text { days/week }\end{array}$ \\
\hline Weight training & $\begin{array}{l}3-4 \text { sessions/week } \\
2-3 \text { sets } \\
6-8 \text { reps/set } \\
2-4 \text { min rest between sets } \\
\text { Tempo }-2: 1: 4\end{array}$ & $\begin{array}{l}4-5 \text { sessions/week } \\
2-3 \text { sets } \\
8-12 \text { reps/set } \\
30-90 \text { sec rest } \\
\text { between sets } \\
\text { Tempo }-2: 1: 4\end{array}$ & $\begin{array}{l}4-5 \text { sessions/week } \\
3 \text { sets } \\
15 \text { reps/set } \\
10-30 \text { sec rest } \\
\text { between sets } \\
\text { Tempo }-2: 1: 4\end{array}$ \\
\hline
\end{tabular}

Reps: Repetitions, min: Minute, sec: Second, METs: Metabolic equivalents

the intervention in the terms of muscular strength, muscular endurance, and flexibility.

\section{DISCUSSION}

Chaouachi (31) studied the effect of aerobic capacity Vo2 max variables among 41 dominant somatotype individuals using the bicycle ergometer method with $p<0.001$ for signs of progress in Vo2 max and revealed that training methods should be designed based on somatotype along with aerobic exercises. In the present study, Vo2 max was observed by a 1 mile test and the exercises were prescribed along with the cardiovascular conditioning in Groups A, $\mathrm{B}$, and $\mathrm{C}$, and the results showed the improvement in cardiovascular endurance with significant value $(p<0.001)$. When compared to the present study with Chaouachi study, the present study also achieved the positive results in cardiovascular endurance. Ryan-Stewart et al. (32) studied the effects of anaerobic capacity on different somatotypes among 36 participants aged between $26.0 \pm 9.8$ using 3RM bench press and $3 R M$ back squats and found that mesomorphs have more muscular power and endurance levels. In the present study, health-related fitness assessment was done which includes both cardiovascular endurance, muscular strength, and endurance tests. The pre-assessment results showed that mesomorphs can perform 1RM leg press in $60-70 \%$ of the body weight, whereas ectomorphs showed around $4-50 \%$ of $1 \mathrm{RM}$ and endomorphs showed $50-60 \%$ of 1 RM. Thus, the present study agrees with the findings of Ryan-Stewart et al. The contrast between the present study and Chaouachi study is that the author utilized the bicycle ergometer for improving the $V_{0} 2$ max, but we have used the treadmill test to find the Vo2 max and the cardiovascular conditioning was given. The contrast between the present study and Ryan-Stewart et al. study is that the author investigates the anaerobic capacity alone by 1 RM methods. Perhaps, the present focussed on overall fitness improvement by implementing a complete fitness regimen.

The exercise was planned based on the results obtained from the health-related fitness assessment. Since the fat $\%$ is 12.46 in Group A individuals, they were prescribed with 8-10 minutes of cardiovascular conditioning to improve cardiovascular endurance. Aerobic exercises primarily activate and work type I muscle fibers and also increase the capillary size and muscle endurance. Individuals with low-fat content 
also required to do some aerobic activity for a minimum of 8-10 minutes/session for around 3 days/ week to improve cardiovascular endurance (33).

Isolated muscular exercises were implemented to activate the muscle contraction, these powerful and strong isolated muscle contractions cause compression in small arteries and increase the peripheral vascular resistance. Regular long-lasting muscle contraction increases the number of mitochondria and increases the size and strength in the myofibrils (34). Endurance exercises activate and promote the slowtwitch muscle fibers, these muscle fibers are capable of producing several repetitions with little force but without fatigue (35-37). In the present study, isolated strengthening exercises and endurance exercises were given based on the session/week, repetitions, duration, tempo, and rest period, respectively.
Increase in the muscle strength and endurance was observed in Groups A, B, and C, as shown in Tables 3-5. Static stretching is shown to be effective in increasing the ROM, if it occurs between 15 and 30 seconds. Cecília F (38) et al studied the effects of static stretching among 45 subjects with hamstring tightness for a period of 6-8 weeks and observed that there is a significant change in the tightened structure. Revealed that a period of 6-8 weeks of static stretching is sufficient to increase the flexibility of hamstrings and back muscles. In the present study, flexibility of the hamstrings was assessed using the sit and reach the box, based on the results of fitness assessment, static stretching techniques were implemented for the individuals in Groups A, B, and C for 3 months and the results showed that there is an improvement in the flexibility.

TABLE 3. Evaluation of health-related fitness parameters in Group A before and after an intervention

\begin{tabular}{|c|c|c|c|c|c|}
\hline \multirow[t]{3}{*}{ S. No. } & \multirow[t]{3}{*}{ Parameters } & \multicolumn{4}{|c|}{ Group -A $(n=15)$} \\
\hline & & \multicolumn{2}{|c|}{ Mean (SD) } & \multirow[t]{2}{*}{$t$} & \multirow[t]{2}{*}{$p$-value } \\
\hline & & (Pre) & (Post) & & \\
\hline 1. & Weight (kg) & $58.66(5.52)$ & $58.2(6.09)$ & 1.46 & 0.401 \\
\hline 2. & $\mathrm{BMI}\left(\mathrm{kg} / \mathrm{m}^{2}\right)$ & $22.94(1.46)$ & $22.75(1.69)$ & 2.54 & 0.531 \\
\hline 3. & Skinfold (Fat \%) & $12.46(3.24)$ & $13.17(3.14)$ & 1.14 & 0.381 \\
\hline 4. & Heart rate $(\mathrm{HR})$ & $142 / 82(10)$ & $126 / 76(8)$ & 10.18 & $<0.001^{*}$ \\
\hline 5. & Cardiovascular endurance & $13.34(1.44)$ & $11.06(2.13)$ & 12.11 & $<0.001^{*}$ \\
\hline 6. & Muscular endurance & $23.53(6.87)$ & $30.13(4.43)$ & 11.56 & $<0.001^{*}$ \\
\hline 7. & Muscular strength & $53.33(12.90)$ & $61.33(10.76)$ & 11.67 & $<0.001^{*}$ \\
\hline 8. & Flexibility & $-1.8(6.9)$ & $2.2(5.6)$ & 9.22 & $<0.001^{*}$ \\
\hline
\end{tabular}

*Statistically significant. SD: Standard deviation

TABLE 4. Evaluation of health-related fitness parameters in Group B before and after an intervention

\begin{tabular}{llcccc}
\hline S. No. & Parameters & \multicolumn{3}{c}{ Group - B $(\mathrm{n}=15)$} \\
\cline { 3 - 5 } & & \multicolumn{2}{c}{ Mean (SD) } & $\mathrm{t}$ & $p$-value \\
\cline { 3 - 5 } & & $71.62(4.12)$ & $72.12(5.11)$ & 3.16 & 0.831 \\
\hline 1. & Weight (kg) & $24.13(1.13)$ & $24.75(1.19)$ & 2.81 & 0.608 \\
2. & BMl $\left(\mathrm{kg} / \mathrm{m}^{2}\right)$ & $23.14(2.34)$ & $23.71(2.71)$ & 2.12 & 0.422 \\
3. & Skinfold (Fat \%) & $148 / 78(12)$ & $122 / 76(10)$ & 11.13 & $<0.001^{*}$ \\
4. & Heart rate (HR) & $14.11(1.22)$ & $12.21(2.12)$ & 10.12 & $<0.001^{*}$ \\
5. & Cardiovascular endurance & $29.13(5.14)$ & $32.18(3.38)$ & 11.85 & $<0.001^{*}$ \\
6. & Muscular endurance & $63.15(11.63)$ & $72.13(9.15)$ & 10.54 & $<0.001^{*}$ \\
7. & Muscular strength & $-2.3(4.5)$ & $3.4(4.9)$ & 10.15 & $<0.001^{*}$ \\
8. & Flexibility & &
\end{tabular}

*Statistically significant. SD: Standard deviation 
TABLE 5. Evaluation of health-related fitness parameters in Group $C$ before and after an intervention

\begin{tabular}{llcccc}
\hline S. No. & Parameters & \multicolumn{3}{c}{ Group - C $(\mathrm{n}=15)$} \\
\cline { 3 - 5 } & & \multicolumn{2}{c}{ Mean (SD) } & t & p-value \\
\cline { 3 - 5 } & & (Pre) & (Post) & \\
\hline 1 & Weight (kg) & $93.46(3.68)$ & $84.28(2.16)$ & 11.12 & $<0.001^{*}$ \\
2 & BMl (kg/m $\left.{ }^{2}\right)$ & $32.46(3.23)$ & $27.35(2.19)$ & 10.41 & $<0.001^{*}$ \\
3 & Skinfold (Fat \%) & $30.12(2.64)$ & $27.51(2.43)$ & 11.32 & $<0.001^{*}$ \\
4 & Heart rate (HR) & $151 / 86(14)$ & $132 / 78(8)$ & 9.32 & $<0.001^{*}$ \\
5 & Cardiovascular endurance & $16.19(1.14)$ & $13.17(1.17)$ & 11.18 & $<0.001^{*}$ \\
6 & Muscular endurance & $10.12(7.13)$ & $17.14(4.26)$ & 10.16 & $<0.001^{*}$ \\
7 & Muscular strength & $59.12(13.47)$ & $67.15(8.22)$ & 11.14 & $<0.001^{*}$ \\
8 & Flexibility & $-4.2(3.4)$ & $1.3(5.3)$ & 9.24 & $<0.001^{*}$ \\
\hline
\end{tabular}

*Statistically significant. SD: Standard deviation, BMI: Body mass index

\section{CONCLUSION}

This study reports about finding the somatotypes, and exercising based on that will provide the best results in health-related fitness components designed by the ACSM. According to the literature and our knowledge, this is the first study to design and implement the health-related fitness based on the somatotypes. To increase the health-related fitness components, a combination of warm-up exercises, flexibility training, cardiovascular conditioning, and weight training exercises must be prescribed and executed holistically based on the assessment results according to the body types. Physical activity or exercise not only maintains a healthy body but it also enhances the dynamic and creative intellectual activity. Fitness is not about building the muscle or endurance alone, neither having a six nor eight pack abdominals, a complete fitness is a combination of good muscular strength and endurance with adequate flexibility and a good proportion of body composition with satisfactory cardiovascular endurance level. The advantage of training based on the somatotypes yields the best results.

\section{ACKNOWLEDGMENT}

We are grateful to R. Mohanasankari and Pooja Kadam for helping us in preparing the manuscript.

\section{REFERENCES}

1. Vertinsky P. Physique as destiny: William H. Sheldon, barbara honeyman heath and the struggle for hegemony in the science of somatotyping. Can
Bull Med Hist 2007;24(2):291-316.

https://doi.org/10.3138/cbmh.24.2.291.

2. Roeckelein J. Psychology among the sciences: Comparisons of numbers of theories and laws cited in textbooks. Psychol Rep 1997;80(1):131.

https://doi.org/10.2466/pr0.1997.80.1.131.

3. Rafter N. Somatotyping, antimodernism, and the production of criminological knowledge. Criminology 2008;45(4):805-33.

https://doi.org/10.1111/j.1745-9125.2007.00092.x.

4. Williams J. In: Tanner JM, editor. The Physique of the Olympic Athlete. (George Allen and Unwin Ltd.; 1965. p. 1064.

https://doi.org/10.1080/00140136508930802.

5. Lewandowska J, Buśko K, Pastuszak A, Boguszewska K. Somatotype variables related to muscle torque and power in judoists. J Hum Kinet 2011;30(1):21-8.

https://doi.org/10.2478/v10078-011-0069-y.

6. Roberts D. In: Malina RM, Bouchard C, editors. Growth, Maturation and Physical Activity. Champaign, Illinois: Human Kinetics Books; 1991. p. 501. Eveleth PB, Tanner JM, editors. Worldwide Variation in Human Growth. $2^{\text {nd }}$ ed. Cambridge: Cambridge University Press; 1990. p. 397. https://doi.org/10.1017/s0021932000020599.

7. Laubach L, Mcconville J. The relationship of strength to body size and typology. Med Sci Sports Exerc 1969;1(4):189-94.

https://doi.org/10.1249/00005768-196912000-00004.

8. Baker P. Weiner JS, Lourie JA, editors. Human Biology. A Guide to Field Methods. Philadelphia, PA: International Biological Programme by Davis: 1970. p. 43-43.

https://doi.org/10.1126/science.167.3914.43.

9. Elazizi L. Design and development of a serious mobile game mathaventure. Int J Adv Res Comput Commun Eng 2019;8:16-21. https://doi.org/10.17148/ijarcce.2019.8903.

10. Heath BH, Carter JE. A modified somatotype method. Am J Phys Anthropol 1967;27:57-74.

11. Kårhus S. Physical education teacher education on the education market who's defining what physical education teachers need to know? Phys Educ Sport Pedagogy 2010;15(3):227-241.

https://doi.org/10.1080/17408980903150139.

12. Faucett J, Rempel D. VDT-related musculoskeletal symptoms: Interactions between work posture and psychosocial work factors. Am J Indust Med 
1994;26(5):597-612.

https://doi.org/10.1002/ajim.4700260503.

13. Amigó I, Alfredo I. Height, weight, somatotype and body composition in elite Spanish gymnasts from childhood to adulthood. Apunts Med Esport 2009;61:18-28.

14. Sanchez-Munoz C, Sanz D, Zabala M. Anthropometric characteristics, body composition and somatotype of elite junior tennis players. Br J Sports Med 2007;41(11):793-9.

https://doi.org/10.1136/bjsm.2007.037119.

15. BarBend. Are the Somatotypes Ectomorph, Mesomorph, and Endomorph Relevant in Training? BarBend; 2019. Available from: https://www.barbend. com/somatotypes-ectomorph-mesomorph-endomorph. [Last accessed 10 November 2019].

16. Ehrman J. ACSM's Resource Manual for Guidelines for Exercise Testing and Prescription. Philadelphia, PA: Wolters Kluwer, Lippincott Williams et Wilkins; 2013.

17. Costanzo D. ACSM certification. ACSM's Health Fitness J 2006;10(4):38-9. https://doi.org/10.1249/00135124-200607000-00011.

18. Paternostro-Bayles $M$. The role of a job task analysis in the development of professional certifications. ACSM Health Fitness J 2010;14(4):41-2.

https://doi.org/10.1249/fit.0b013e3181e3488a.

19. Ferguson B. ACSM's Guidelines for Exercise Testing and Prescription $9^{\text {th }}$ Ed. J Can Chiropr Assoc 2014;58(3):328.

20. American College Of Sports Medicine. Acsm's Guidelines for Exercise Testing and Prescription. $8^{\text {th }}$ ed. Philadelphia, PA: Wolters Kluwer Health; 2010.

21. Febbraio M, Pedersen B. Muscle-derived interleukin-6: Mechanisms for activation and possible biological roles. FASEB J 2002;16(11):1335-47. https://doi.org/10.1096/fj.01-0876rev.

22. Ylinen $J$, Kankainen $T$, Kautiainen $H$, Rezasoltani $A$, Kuukkanen $T$, Häkkinen A. Effect of stretching on hamstring muscle compliance. J Rehabil Med 2009;41(1):80-4. https://doi.org/10.2340/16501977-0283.

23. Lassarre C, Girard F, Durand J, Raynaud J. Kinetics of human growth hormone during submaximal exercise. J Appl Physiol 1974;37(6):826-830. https://doi.org/10.1152/jappl.1974.37.6.826.

24. Richter E, Kiens B, Saltin B, Christensen N, Savard G. Skeletal muscle glucose uptake during dynamic exercise in humans: Role of muscle mass. Am J Physiol Endocrinol Metab 1988;254(5):E555-61. https://doi.org/10.1152/ajpendo.1988.254.5.e555.

25. Romer L, Polkey M. Exercise-induced respiratory muscle fatigue: Implications for performance. J Appl Physiol 2008;104(3):879-88. https://doi.org/10.1152/japplphysiol.01157.2007.

26. Kemppainen J, Aalto S, Fujimoto T, Kalliokoski K, Långsjö J, Oikonen V, et al. High intensity exercise decreases global brain glucose uptake in humans. J Physiol 2005;568(1):323-32.

https://doi.org/10.1113/jphysiol.2005.091355.
27. Sekir U, Arabaci R, Akova B, Kadagan S. Acute effects of static and dynamic stretching on leg flexor and extensor isokinetic strength in elite women athletes. Scand J Med Sci Sports 2009;20(2):268-81.

https://doi.org/10.1111/j.1600-0838.2009.00923.x.

28. Colberg S, Sigal R, Fernhall B, Regensteiner J, Blissmer B, Rubin R, et al. Exercise and Type 2 diabetes: The American college of sports medicine and the american diabetes association: Joint position statement. Diabetes Care 2010;33(12):e147-67.

https://doi.org/10.2337/dc10-9990.

29. Rochester C, Vogiatzis I, Holland A, Lareau S, Marciniuk D, Puhan M, et al. An official American thoracic society/European respiratory society policy statement: Enhancing implementation, use, and delivery of pulmonary rehabilitation. Am J Respir Crit Care Med 2015;192(11):1373-86. https://doi.org/10.1164/rccm.201510-1966 $6^{\text {st }}$.

30. Spruit M, Burtin C, De Boever P, Langer D, Vogiatzis I, Wouters E, et al. COPD and exercise: Does it make a difference? Breathe 2016;12(2):e38-49. https://doi.org/10.1183/20734735.003916.

31. Chaouachi M. Effects of dominant somatotype on aerobic capacity trainability. Br J Sports Med 2005;39(12):954-9. https://doi.org/10.1136/bjsm.2005.019943.

32. Ryan-Stewart H, Faulkner J, Jobson S. The influence of somatotype on anaerobic performance. PLoS One 2018;13(5):e0197761.

https://doi.org/10.1371/journal.pone.0197761.

33. Pescatello L, Franklin B, Fagard R, Farquhar W, Kelley G, Ray C. American college of sports medicine position stand. Exercise and hypertension. Med Sci Sports Exerc 2004;36(3):533-53.

https://doi.org/10.1249/01.mss.0000115224.88514.3a.

34. Bompa T. Variations of periodization of strength. Strength Cond $J$ 1996;18(3):58.

https://doi.org/10.1519/1073-6840(1996)018<0058:vopos>2.3.co;2.

35. Mchugh M, Magnusson S, Gleim G, Nicholas J. Viscoelastic stress relaxation in human skeletal muscle. Med Sci Sports Exerc 1992;24(12):1375-82. https://doi.org/10.1249/00005768-199212000-00011.

36. Bandy W, Irion J. The effect of time on static stretch on the flexibility of the hamstring muscles. Phys Ther 1994;74(9):845-50.

https://doi.org/10.1093/ptj/74.9.845.

37. Ferreira G, Teixeira-Salmela L, Guimares C. Gains in flexibility related to measures of muscular performance: Impact of flexibility on muscular performance. Clin J Sport Med 2007;17(4):276-81. https://doi.org/10.1097/jsm.0b013e3180f60b26.

38. Aquino C, Fonseca S, Gonçalves G, Silva P, Ocarino J, Mancini M. Stretching versus strength training in lengthened position in subjects with tight hamstring muscles: A randomized controlled trial. Manual Ther 2010;15(1):26-31.

https://doi.org/10.1016/j.math.2009.05.006. 